\title{
Origen, formación y posible significado de los esferocristales intestinales de Eucyclops serrulatus (Fisher, 1851), (Crustacea, Copepoda)
}

\author{
M. Durfort
}

Dpto. Morfología Microscópica, Facultad de Biología, Universidad de Barcelona

\begin{abstract}
SUMMARY
ORIGIN, FORMATION AND POSSIBLE SIGNIFICATION OF THE SPHEROCRYSTALS IN THE MIDGUT CELLS OF Eucyclops sermilatus (FISCHER, 1981) (CRUSTACEA, COPEPODA).
\end{abstract}

The formation of calcareous concretions in Eucyclops serrulatus bears a previous arising of big vesicles, in the inner part of which an organic (mainly glucoproteinic) matrix accumulates and takes place the settling of salts incorporated by type B cells of the intestinal epithelium. Spherocrystals accumulated in the vesicles of this species have three origins, which take place simultaneously: a) from expansions of ergastoplasm after loosing its ribosomes; b) from mitochondria; c) from macroinvaginations of the apical pole of the plasmalemma in the intestinal type B cells. This is a very particular fact and cannot be found in specific bibliography.

Observing these concretions in the previous stages of ecdysis and their vanishing by redisolution after molting, suggests us that this endogenous calcium is a store to be transferred to haemolymp and from this to the cuticle when its formation is completing, in order to be definitively consolidated. However, in this process also takes part, obviously, exogenous calcium directly absorbed by the integument. It is also considered that released calcium is related to vitellogenesis, since the synthesis of lipovitellin (usual component of yolk protein) requires the incorporation of vitellogenin from haemolymph. In this incorporation, calcium is one of the limiting factors. A histochemical study by means of electronic microscope and an analy tical X-ray microprobe study of the spherocrystals are proposed.

\section{INTRODUCCION}

La presencia endocelular de esferocristales o concreciones de constitución bifásica (matriz orgánica y depósitos de sales inorgánicas de diversa indole) ha sido descrita preferentemente en los ciegos intestinales de
Crustáceos, (DONADEY, 1969; GRAF, 1971 ; 1977) en el hepatopáncreas de diversas especies de Decápodos, BECKER et. al. (1974) y en el de Moluscos, (ABOLINSKROGIS, 1970; RONDELAUD, 1976; DURFORT, 1982). 
La naturaleza química de dichas concreciones en los Crustáceos suele ser calcárea (carbonatos, fosfatos y sulfatos); habitualmente tienen carácter de reserva y están relacionadas con la consolidación de la cuticula, (DRACH, 1937, 1939 y 1942; GRAF, 1969). Es por ello altamente interesante seguir la formación y posterior almacenamiento de estas concreciones antes y después de la ecdisis, es decir observar la posible ecomorfosis endocelular.

En ciertos casos, los acúmulos calcáreos que presentan los Crustáceos son de tipo extracelular, con dimensiones muy variables que pueden oscilar de $5 \mathrm{~mm}$. a $7 \mathrm{~cm}$. El aspecto puede ser discoidal o hemisférico, como los gastrolitos de los Decápodos (adheridos a nivel de la cutícula gástrica, en la zoná del cardias) (HUSSON, 1952; GRAF, 1974 y 1978) o formando bastoncillos de $1 \mathrm{~mm}$. de longitud, simétricamente dispuestos a ambos lados del intestino medio, como los descritos por NATH (1972) en Spelaeomysis.

No siempre las concreciones tienen un significado de reserva. Esferocristales con carácter excretor y de constitución heterogénea, pero con un predominio de uratos, han sido frecuentemente descritos en los tubos de Malpighi de numerosas especies de Insectos (MARTOJA, 1971). Morfológicamente son muy parecidos a los esferocristales de reserva, ya que ambas formaciones se caracterizan por tener una zonación concéntrica muy marcada y de elevada densidad a los electrones. En este sentido cabe destacar los traba-. jos de LHONORE (1976 a y b), BALLANDUFRANCAIS $(1971,1972$ y 1980) JEANTET et. al. (1980) y HUMBERT (1978a y 1979) sobre la bioacumulación de metales pesados presentes en diversos insecticidas en estas concreciones.

En los Colémbolos, al no existir tubos de Malpighi, es el mesénteron quién desempeña la función excretora equivalente y los esferocristales endocelulares acumulados se eliminan o por extrusión apocrina de la celula intestinal; o por degeneración celular (excreción holocrina) o bien por renovación periódica del epitelio intestinal después de cada muda (HUMBERT, 1974, 1977, 1978 b y 1979; LANGAREYREL, 1980).
La presencia de esferocristales en el intestino de insectos no siempre está supeditada a la falta de tubos de Malpighi como en el caso anterior. Los hallazgos efectuados por BALLAN-DUFRANÇAIS (1972) en diversas especies de Ortópteros, por SOHAL et. al. (1977) en Dípteros, así como los de JEANTET et. al. (1974); TURBECK (1974) y WAKU et. al. (1971) en larvas de Lepidópteros y los de GOURANTON (1968) en Homópte ros se refieren a concreciones de 0,8 a $2 \mu \mathrm{d}$. diámetro con carácter excretor y origen $\mathrm{p}$. lifilético.

En los artrópodos aparte de hallar concrı ciones endocelulares en el epitelio intestinal o en el de los tubos de Malpighi, ocasional mente, se han descrito en otros órganos. En las glándulas anejas al aparato reproductor masculino de Blatella germanica, cuyas células tienen simultáneamente función excretora y secretora, BALLAN-DUFRANCAIS (1970) describe la presencia de concreciones, PERRELET et. al. los hallan en fotoreceptores (1978) y PETIT (1970) asi como ZERBIB (1980) ocasionalmente los hallan en oocitos.

Las concreciones endocelulares se hallan normalmente en grandes vesículas o litosomás, término dado por ANDRÉ et. al. (1967) a vesículas en cuyo interior se acumulan concreciones calcáreas y que provenían del retículo endoplasmático. El origen de las vesículas acumuladoras de sales inorgánicas es muy heterogéneo, varía según las especies e incluso en una misma celula pueden coexis* tir dos o tres orígenes (DURFORT, 1982).

\section{MATERIAL Y METODOS}

Los ejemplares de Eucyclops semulatus estudiados proceden de diversas muestras recogidas durante el año 1980 en Banyoles (Girona) por miembros del Departamento de Ecología de la Facultad de Biología de la Universidad de Barcelona.

Se procesó el material para su estudio con los microscopios electrónicos de barrido y de transmisión, siguiendo la metodologia habitual para ello, es decir, una prefijación con 
glutaraldehido-paraformaldehido al 3,5\% tamponado con Sörensen o con cacodilato sódico $0,1 \mathrm{~N}$, a pH 7,2-7,3 durante dos horas a $4^{\circ}$ C. Postfijación con tetraóxido de osmio al $2 \%$ igualmente tamponado durante $1 \mathrm{~h}$. 30 min. a $4^{\circ} \mathrm{C}$

Los ejemplares, tras una cuidadosa deshiđratación con una serie de graduación ascen. dente de alcohol $\mathrm{u}$ acetona, se separaron en dos lotes.

a) Para su estudio al microscopio electrónico de barrido se completó la deshidratación con una serie de graduación ascendente de alcohol absoluto $\mathrm{u}$ acetona $\mathrm{y}$ acetato de amilo, antes de someterlos a la técnica del punto crítico para su total desecación. La metalización con oro, efectuada con la técnica del "sputtering", es la última etapa del procesado de los ejemplares. La observación se llevó a cabo con un microscopio electrónico Cambridge Stereoscan S-4 del Servicio de Microscopia Electrónica de la Universidad de Barcelona y habitualmente a $20 \mathrm{Kv}$.

b) Los ejemplares destinados a ser estudiados con el microscopio electrónico de transmisión, tras una cuidadosa deshidratación con una serie ascendente de alcohol ab. soluto $\mathrm{u}$ acetona y óxido de propileno, se incluyeron en Araldita-Epon o con 'Spurr", éste último al ser un plástico de menor viscosidad penetra más fácilmente a través de la cutícula de los copépodos, por lo que la calidad de los cortes ultrafinos es superior a la que se consigue tras la inclusión con los plásticos habitualmente usados para incluir muestras "blandas".

Los esferocristales, motivo de la presente nota, ofrecen graves dificultades en ultramicrotomia ya que en ocasiones saltan de la muestra al efectuar los cortes. Por ello quedan vesículas vacias a la vez que se estropea considerablemente el filo de la cuchilla de vidrio.

Habitualmente se tiñeron los cortes semifinos con azul de metileno al $1 \%$ ó con azul de toluidina al $1 \%$. La visualización óptima de las concreciones al microscopio óptico se logra tras un montaje con D.P.X. de los cortes semifinos.

Los cortes ultrafinos, obtenidos con un ultramicrótomo OMU (Reichert) fueron habitualmente contrastados con acetato de uranilo y citrato de plomo, éste último preparado según la técnica de REYNOLDS. Las observaciones se efectuaron con un microscopio electrónico de transmisión Philips EM 200 y Philips EM 300 del Centro anteriormente citado y $60 \mathrm{Kv}$.

\section{RESULTADOS}

La mucosa del tramo medio y posterior del intestino de $E$. semulatus está formada por dos tipos de celulas (A y B) que difieren por presentar una distribución y desarrollo desigual de sus estructuras citoplasmáticas, a la vez que desempeñan distintas funciones. Contactos del tipo de las máculas adhaerens se hallan en las proximidades del polo apical de ambos tipos celulares.

El carácter diferencial más acusado entre las células de tipo $\mathrm{A}$, absorbentes y numéricamente más abundantes y las de tipo B es la presencia en éstas últimas de vesículas de 0,5 a 6 micras de diámetro de origen polifilético y de contenido granuloso-fibroso, más o menos compactado, según la etapa de su formación.

El plasmalema de las células de tipo B presenta en el polo apical numerosos microvilli, raramente arrosariados, de 2 micras de longitud y relativamente gruesos, de unas 0,3 micras de diámetro (figs. $2,3,4,5$ y 6 ) entre los cuáles hay abundantes formaciones de endocitosis, de tipo pinocítico (fig. 4). Un glucocálix bien desarrollado forma una capa granulosa-fibrosa, muy densa a los electrones y de unas 3 micras de grosor, que indudablemente favorece los procesos que tienen lugar a este nivel (fig. 4).

En determinadas fases del ciclo biológico se forman unas macroinvaginaciones en el polo apical de las celulas de tipo B (figs. 3 y 6) que se cierran por la parte próxima a la luz intestinal, quedando liberadas en el citoplasma y dando lugar a grandes vesiculas de 8 a 10 micras de diámetro por término medio, interiormente tapizadas por microvilli (figs. 5,6 y 7 ). 
La evolución de las macrovesículas que se forman a partir del plasmalema sigue un proceso cíclico por el cuál se desorganizan en primer lugar los microvillis, fusionándose el glucocálix que los envolvía con el contenido de las digitaciones y constituyéndose una matriz o estroma, eminentemente glucoproteínico en la que se asientan posteriormente las sales minerales que había en suspensión en la luz intestinal (figs. 8 y 15) con una progresiva consolidación de las mismas.

La proliferación de estas macrovesículas coincide con la aparición de numerosas mitocondrias de diverso tamaño y forma, de matriz muy poco densa a los electrones y con escasas crestas (fig. 15). En ocasiones hay agregados de dos o cuatro condriosomas, siendo frecuente hallar mitocondrias anulares en cuyo interior suele haber otra esférica (fig. 10).

Al incremento de las mitocondrias en las proximidades de las vesículas se suma otra proliferación en el polo basal de la célula, cuya membrana presenta abundantes invaginaciones a la vez que en dicha zona hay que destacar la presencia de algunos cuerpos multivesiculares (fig. 10). Los condriosomas de esta zonal basal, así como los de la región media de la cellula tienen tamaños y formas muy variadas. Las mitocondrias frecuentemente se cavulan alrededor de otras esfericas (fig. 10) y sus crestas no siempre adoptan una disposición perpendicular al eje mayor del orgánulo sino que se redistribuyen adoptando una disposición en paralelo, lo cuál ha de tener una indudable incidencia en el rendimiento fisiológico del orgánulo. Frecuentemente queda una área de citoplasma, altamente granulosa, secuestrada entre las dos mitocondrias. La última etapa de la metamorfosis mitocondrial es la formación de una vesicula de 0,5 a 1 micras de diámetro, por alargamiento de una mitocondria y posterior fusión de sus extremos (figs. 10,11 y 12).

Las células epiteliales de tipo B que nos ocupan presentan, en un momento determinado, un ergastoplasma bien desarrollado dispuesto periféricamente al núcleo (fig. 14). En ciertos tramos las vesículas ergastoplasmáticas pierden los ribosomas y el retículo endoplasmático devenido liso origina por dilatación de sus sáculos unas macrovesiculas (litosomas) en cuyo interior se irá progresivamente compactando un material de tipo eminentemente proteínico que constituirá la trama orgánica de la futura concreción mineral.

Paralelamente a la proliferación de las ve. sículas acumuladoras de sales minerales, presuponiblemente calcáreas, tiene lugar un incremento de gránulos lipídicos de 2 micras de diámetro. Dichas inclusiones lipídicas tienen una morfología poco habitual, en el sentido que el núcleo central de la inclusión de aspecto homogéneo y escasa densidad a los

\section{LAMINA I}

Fig. 1. Eucyclops semulatus observado con el microscopio electrónico de barrido (50 x). Fig. 2. Sección transversal del tramo medio del intestino de E. Serrtlatus perteneciente a un ejemplar que había mudado recientemente. Nótese la ausencia de concreciones en las células epiteliales de la mucosa in testinal. (5.000 x). Fig. 3. Fragmento de la mucosa intestinal en el que se aprecia la formación en el polo apical de una célula de tipo B, de una macroinvaginación ( $\star$ ) tapizada interiomente por numerosos microvillis. En una de las diversas vesículas citoplasmáticas se aprecia una bien conformada concreción (flecha). ( $8.000 \mathrm{x}$ ). Fig. 4. Detalle de las microvillis y de las formaciones de endocitosis de una célula de tipo $B$. Obsérvese el bien desarrollado glucocálix (g). $(24.000 \mathrm{x})$. Fig. 5 . Vesículas en đistintas fases de elaboración de concreciones minerales. $(22.200 \mathrm{x})$. Fig. 6 . Detalle de una macroinvaginación incorporada al citoplasma de una célula de tipo $B(\star)$. Obsérvese el núcleo $(N)$ en posición basal $(25.000 x)$. Fig. 7. Dos macrovesículas con numerosos microvillis en su interior, junto con mitocondrias $(30.000 \mathrm{x})$. Fig. 8. Detalle de vesículas con matriz orgánica granulosa-fibrosa, parcialmente rodeada por un círculo de elevada densidad a los electrones (flechas) que constituyen la parte inorgánica del esfero cristal. $(25.000 \mathrm{x})$. 


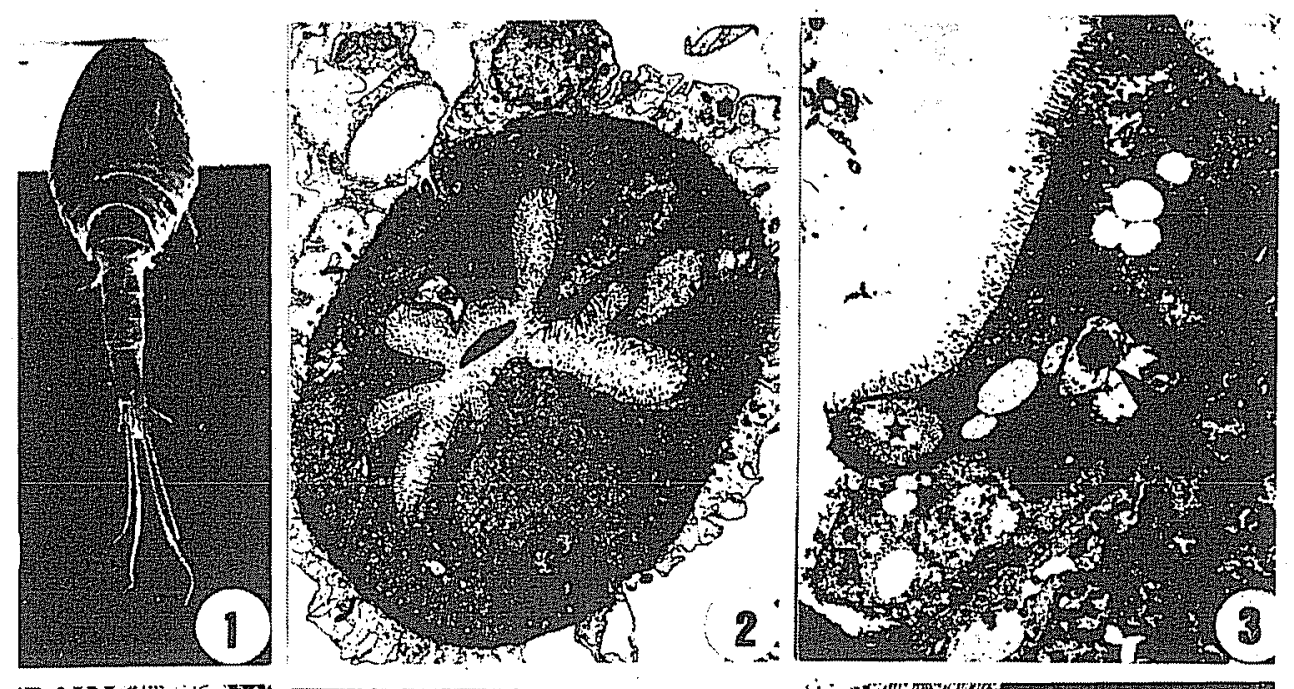

Not
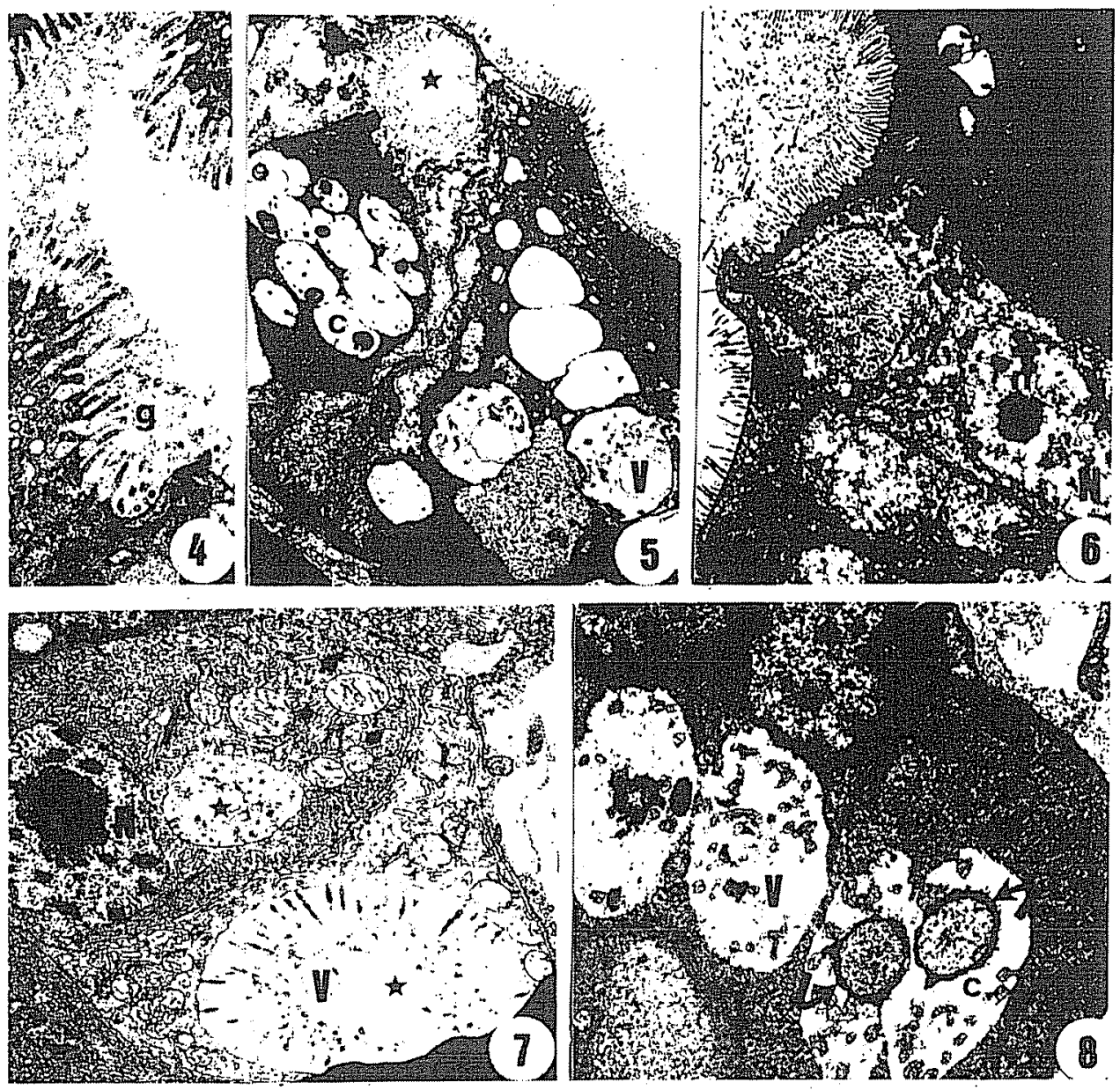
electrones es circundado por un halo más bien fibroso de mayor densidad a los electrones, exteriormente delimitado por una zona de densidad intermedia (fig. 13). Este tipo de inclusión nos recuerda el aspecto ultraestructural de las plaquetas vitelinas de determinadas especies de Moluscos; por lo que basándonos exclusivamente en su morfología y densidad a los electrones podria pensarse que en realidad se trata de inclusiones lipoproteícas y que deben tener un significado degenerativo en la célula epitelial considerada, aunque hay que señalar la ausencia de formaciones lisosómicas (estructuras propias de las células en procesos seniles o patológicos).

Cuando la celula se halla en su estado de "almacenamiento", o sea en el momento que la génesis de los esferocristales llega a su etapa final, el citoplasma presenta grandes áreas invadidas por las vesículas de distinta procedencia. Estas tienen una matriz orgánica cada vez más compactada y en su periferia aparece de manera gradual un halo de elevada densidad a los electrones (figs. 8 y 15).

Los esferocristales que aparecen finalmente en las células de tipo B del epitelio in testinal de Eucyclops serrulatus tienen de 2 a 8 micras de diámetro y presentan ultrastructuralmente la zonación concéntrica característica de las concreciones de sales minerales o incluso de uratos. El límite exterior del esferocristal, la membrana del litosoma, llega a desaparecer (fig. 16). No hemọs presenciado formaciones gemelas o triples, en nuestro material las concreciones se hallan bien individualizadas y su nucleoide aparece poco delimitado.

Finalmente, en los ejemplares que han experimentado la ecdisis, las concreciones em- piezan a disgregarse por la periferia, presentando primero un aspecto dentado y posteriormente estrellado (fig. 17), lo que indica el inicio de la redisolución de la concreción.

\section{DISCUSION Y CONCLUSIONES}

Los dos tipos celulares que constituyen el epitelio intestinal de Eucyclops serrulatus son morfológicamente y funcionalmente equivalentes a los descritos en Cyclops strenuus (DURFORT, 1981 b). Sin embargo a diferencia de lo que acontece en $C$. strenuus, en que las concreciones se originan únicamente a partir de formaciones mielínicas que aparecen en grandes vesiculas (litosomas) procedentes del retículo endoplasmático; en $E$. serrulatus aquellas tienen tres orígenes:

a) a partir del retículo endoplasmático,

b) a partir de las mitocondrias y

c) a partir del plasmalema del polo apical de las células de tipo B.

De estos tres orígenes que se dan simultáneamente en la misma célula, el más frecuentemente descrito en los Crustáceos (GRAF, 1971), asi como en las células de los tubos de Malpighi de los Insectos (HUMBERT, 1971) es el primero.

WIGGLESWORTH \& SALPETER (1962) en los tubos de Malpighi de Rhodnius proli$x u s$ describen un posible origen mitocondrial de las concentraciones, siendo ésta la única cita hallada en la bibliografía consultada, aunque los condriosomas, en ocasiones, pueden acumular inclusiones de tipo paraplasmáticas: glucógeno, glóbulos lipidicos, etc. (DURFORT, 1981 a) y en la mayoría de las talasemias es habitual hallar granulaciones de ferritina en la matriz mitocondrial (BESSIS

\section{LAMINA II.}

Fig. 9. Macrovesículas (V) con matriz finamente granulosa en las cuales se aprecia el inicio de la formación del nucleoide del futuro esferocristal $(38.000 \mathrm{x})$. Fig. 10 . Mitocondria anular que engloba a otra $(\mathrm{M})$, entre ambas se aprecia una área citoplasmática finamente granulosa $(32.000 \mathrm{x})$. Fig. 11 . Obsérvese la formación de vesículas de matriz granulosa a partir de una mitocondria (flecha). Nótese las invaginaciones de la membrana basal así como un fragmento de la túnica muscular (FM). (20.000 x). Fig. 12. Detalle de la formación de una vesícula a partir de un condriosoma (flechas). (54.000 x). Fig. 13. Inclusiones lipídicas (L), frecuentes en la fase álgica de la bioacumulación. $(45.000 \mathrm{x})$. Fig. 14. Formación de una vesícula a partir del retículo endoplasmático liso, procedente del ergastoplasma (ER) por pérdida de ribosomas $(45.000 \mathrm{x})$. 

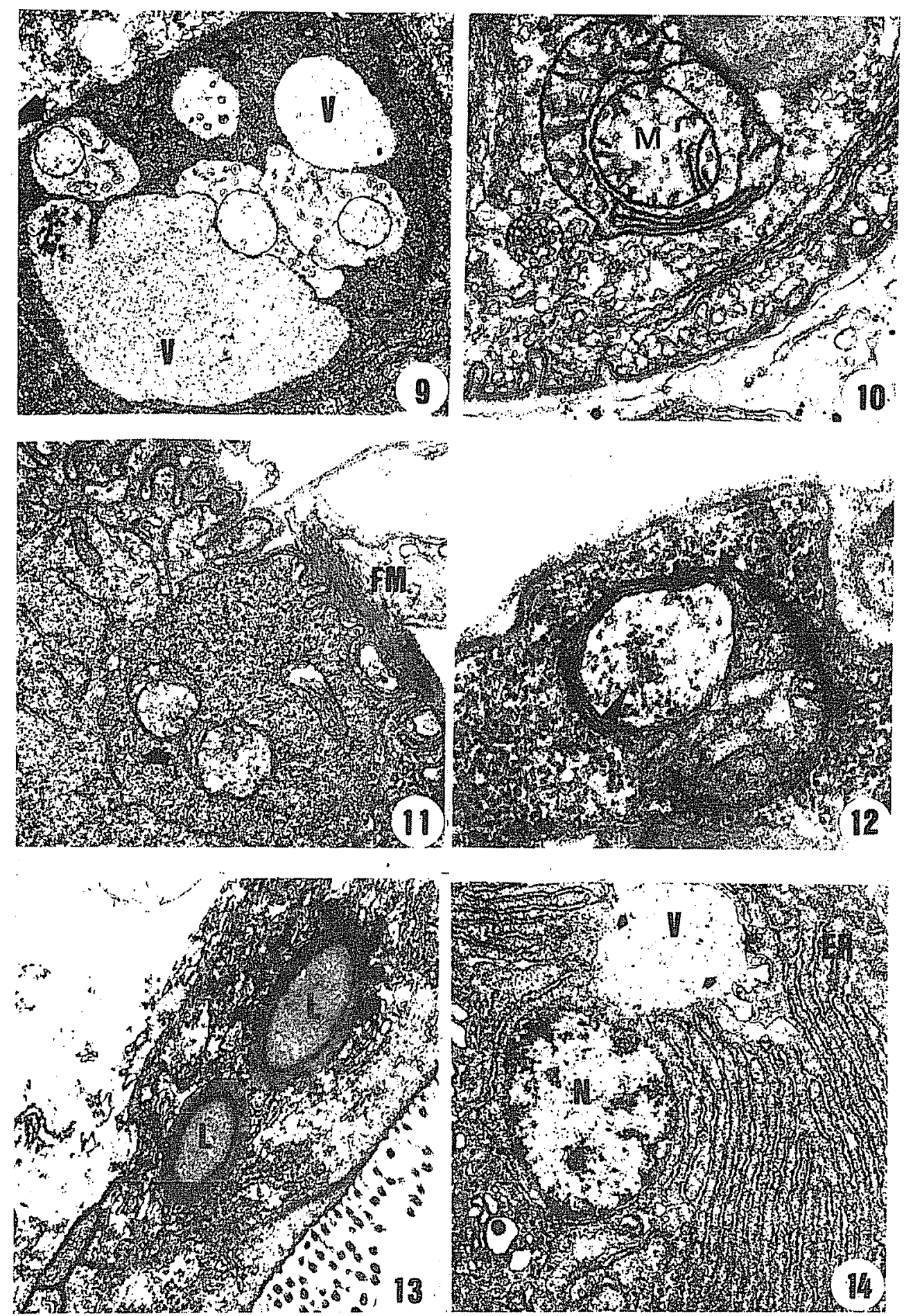
et. al. 1957 y 59). HUMBERT (1978 b) encuentra asimismo partículas de lantano en los condriosomas tras haberlo administrado a través de la dieta de diversas especies de insectos.

La vesiculación intramitocondrial que observamos recuerda enormemente la adoptada por los condriosomas de las células de la adenohipófisis en proceso degenerativo (BARGMANN \& KNOOP, 1960). Si bien, en las celulas de tipo B de la mucosa intestinal de $E$. serrulatus no aparecen formaciones típicamente degenerativas, en ninguna de sus modalidades, como puedan ser los lisosomas, descritos por GOURANTON (1968).

Efectivamente, en nuestro copépodo, la presencia de esferocristales no va acompañada de formaciones lisosómicas tan habituales en las células en vías de degeneración y cargadas de concreciones de tipo excretor, como los reseñados por SOHAL et. al. (1977) en el epitelio intestinal de la mosca doméstica o como los hallados por DURFORT (1981 a) en las células de tipo $C$ del hepatopáncreas de determinad as especies de Moluscos Poliplacóforos. En ambos casos los lisosomas intervienen directamente en la consolidación, tras acúmulo previo de sales inorgánicas y de una matriz proteica, de las concreciones excretoras (SOHAL et. al., 1977) o de reserva (DURFORT, 1981 b).

En otros casos en los lisosomas se acumulan diversos cationes, que sin llegar a constituir esferocristales constituyen un mecanismo de desactivación del elemento, como señalan JEANTET et. al. (1974 y 1980) en procesos de detoxicación de insectos tratados con insecticidas o CHASSARD-BOUCHAUD (1981) en el hepatopáncreas de Pontastacus leptodactylus. En este caso tras someter los ejemplares a una intoxicación con metalotioneinas, se acumulan en los he- terofagosomas de las células $\mathrm{R}$ cadmio, azufre, zinc y cobre que son perfectamente detectados por microanálisis con espectrografía de rayos $X$.

La formación de criptas, es decir de invaginaciones del plasmalema del polo apical de la celula de tipo B y la posterior liberación de macrovesiculas interiormente tapizadas de microvilli no ha sido hallada en la amiplia bibliografía consultada sobre el tema. Unicamente GRAF (1971) en Orchestia cavimana describe un in teresante fenómeno por el cual las membranas laterales de las células epiteliales de los ciegos posteriores del amfípodo presentan profundas invaginaciones que dan lugar a un tortuoso sistema canalicular-vesicular axoplasmático, en cuyo interior se van precipitando y acumulando sales minerales que posteriormente alcanzarán un grado de compactación tal que darán lugar a la clásica configuración de los esferocristales, en este caso de tipo excretor y no de reserva.

Por otra parte el incremento mitocondrial registrado en las proximidades de los litosomas, sea cual fuere su origen, durante la fase de organización del esferocristal debe in terpretarse como una respuesta a un mayor requerimiento energético en la fase bioacumuladora.

$\mathrm{Al}$ igual que en Cyclops strenuus, los esferocristales hallados en las células de tipo B son eminentemente calcáreos, si bien su composición cuantitativa y cualitativa está pendiente de unos análisis con Rayos X. El hecho de dar reacción positiva al rojo de alizarina y a diversas impregnaciones argénticas aplicadas en cortes obtenidos por inclusión en parafina, hacen pensar en la presencia mayoritaria de calcio, si bien es de esperar que haya otros cationes.

El relacionar la redisolución de las concreciones con los períodos de muda de los ejem-

\section{LAMINA III}

Fig. 15. Diversas etapas de la consolidación del material inorgánico en la trama orgánica granulosa-fibrosa sea de origen mitocondrial o del retículo endoplasmático, de las vesículas (V). (40.000 x). Fig. 16. Aspecto ultraestructural de un esferocristal del epitelio intestinal de $E$. semrlatus. $(64.000 x)$. Fig. 17. Inicio de la etapa de redisolución de la concreción mineral. Este aspecto estrellado es muy frecuente al iniciarse la ecdisis. $(64.000 \mathrm{x})$. 


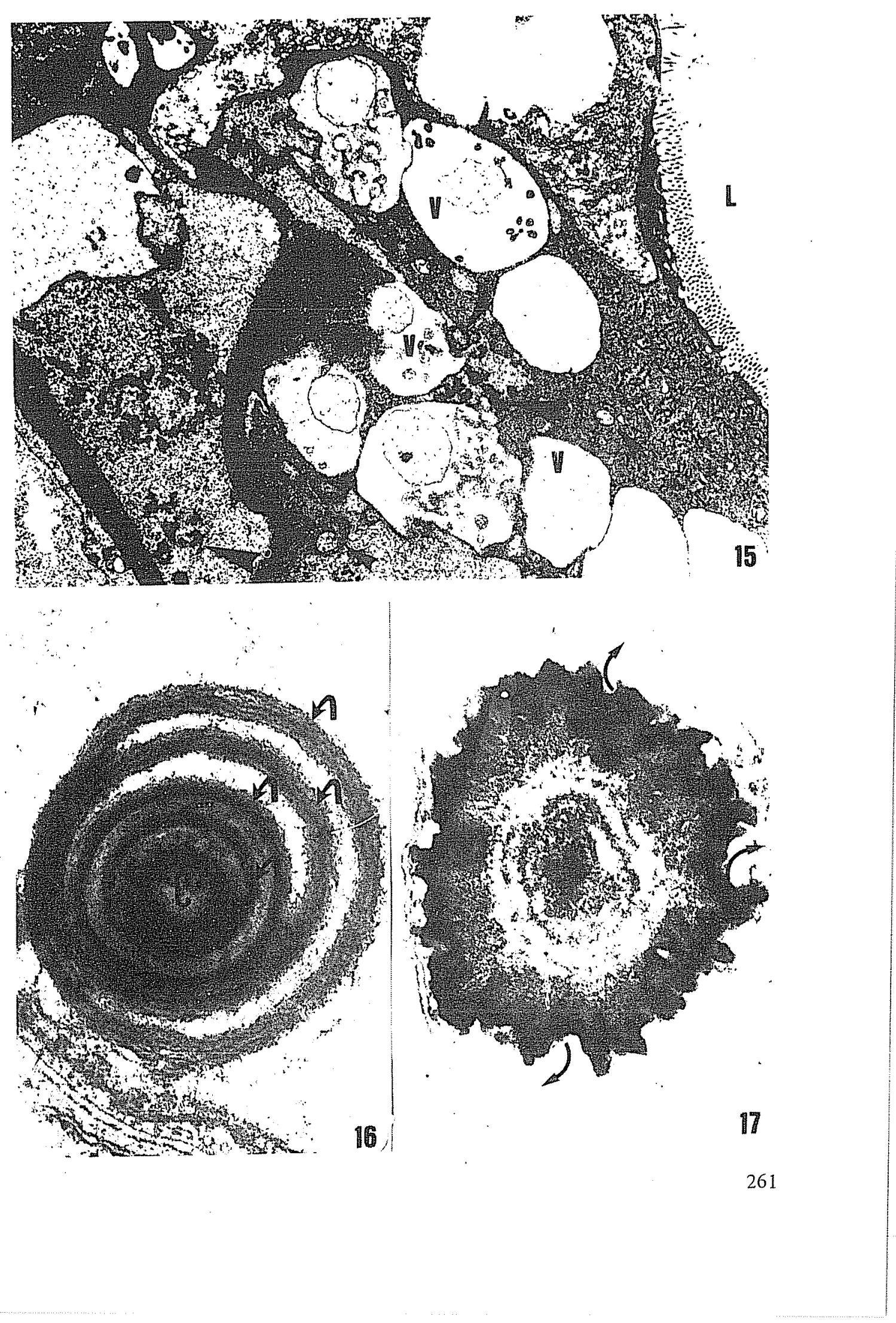


plares, al igual que GRAF (1974) y otros au tores, es porque consideramos que este calcio intracelular es una reserva endógena que tras la incidencia de las hormonas reguladoras de la muda se redisuelve y via hemolinfa llegará, tras la ecdisis, a la cutícula neoformad a para su consolidación. Como en los copépodos el tracto digestivo es el único órgano, hasta el momento descrito, que presenta la capacidad de almacenarlo ya que carecen de glándula digestiva y de formaciones extracelulares tipo gastrolito.

Cabe señalar que el tracto digestivo de Mytilicola intestinalis, copépodo endoparásito de la glándula digestiva del mejillón, carece de dichas formaciones acumuladoras de sales (DURFORT, 1975 y 1977) lo que se interpreta al hecho de que presenta una cutícula sumamente simplificada por el régimen endoparasitario del copépodo. Por ello no hay problemas de consolidación del tegumento ya que conviene que éste sea altamente difusible.

Hemos constatado que las fases en que el epitelio intestinal de Eucyclops serrulatus carecen de concreciones endocelulares o bien éstas se hallan en fase de degradación o coincide con la ecdisis y con la culminación de la vitelogenesis.

Los estudios fisiológicos y ultraestructurales llevados a cabo por CHARNIAUX-COTTON el. al. (1981) sobre sexología y reproducción de crustáceos, constatan la necesidad de altos niveles de calcio por parte de los oocitos, para la captación de la vitelogenina de la hemolinfa que es una hormona imprescindible para la síntesis de la lipovitelina la cuál es un componente habitual de las plaquetas vitelinas.

Por todo ello consideramos, en principio, que los esferocristales hallados en las células de tipo B de la mucosa intestinal de Eucyclops semulatus, al igual que los descritos en Cyclops strenuius, son de tipo de reserva y no excretores, jugando dos papeles de máximo interés en dichas especies: consolidación de la cutícula tras la ecdisis e intervención en la captación de la vitelogenina por parte del oolema de los oocitos en previtelogénesis, en el momento en que los ejemplares han alcanzado la madurez sexual.

BIBLIOGRAFIA

ABOLINS-KROGIS, A. 1970. Electron Microscope Studies of the Intracellular Origin and Formation of Calcifying Granules and Calcium Spherites in the Hepatopancreas of the Snail, Helix pomatia, L. Z. Zellforsch., 108: 501-515.

ANDRÉ, J.; \& FAURE-FREMIET, E. 1967. Formation et structure des concrétions calcaires chez Prorodon Morgani, Kahl. J. Micr, 6: 391398.

BALLAN-DUFRANÇAIS, C. 1970. Données cy tophysiologiques sur un organe excréteur particulier d'un insecte, Blatella germanica, L. (Dicty op tère). Z. Zellforsch., 109: 336-355.

1972. Uitrastructure de l'iléon de Blatella germanica. Localisation, genèse et composition des concrétions minérales in tra-cytoplasmiques. $Z$. Zellforsch., 133: 163-179.

B A. LAN-DUFRANCAIS, C.; JEANTET, A.Y \& MARTOJA, R. 1971. Composition ionique et signification physiologique des accumulations minérales de l'intestin moyen des Insectes. C.R. Acad. Sc. Paris, 273: 173-176.
BARGMANN, W. \& KNOOP, A. 1960. Vakuolenbildung und Mitochondrien. Z. Zellforsch., 51 : 456-460.

BECKER, G.L.; CHEN, C.H.; GREENAWALT, J.W. \& LEHNINGER, A.L. 1974. Calcium phosphate granules in the hepatopancreas of the blue crab Callinectes sapidus, J. Cell Biol. 61: 316-326.

BESSIS, M. \& BRETON-GORINS, J. 1957. Accumulation de granules ferrugineux dans les mitochondries des erythroblastes. Comp. Rend. Acad. Scien. Paris, 144: 2.846-2.849.

1959. Ferritin and ferruginous micelles in normal ery throblast and hypochromic hypersidere. mic anemias. Blood, 14: 423-428.

CHARNIAUX-COTTON, H. 1981. Experimental studies of reproduction in Malacostraca Crustaceans. Description of vitellogenesis and of its endocrine control. Advances in Invertebrate Reproduction. Elsevier North Holland, págs. 177186, New York

CHASSARD-BOUCHAUD, C. 1981. Rôle des 
lysosomes dans les phénomène de concentration du cadmium. Microanalyse par spectrographie des rayons X. Comp. Rend. Acad. Sc. Paris, 293: 261-265.

DONADEY, C. 1969. La fonction absorbante des caecums digestifs de quelques Crustacés Isopodes marins, étudiée au microscope électronique Comp. Rend. Acad. Sc. Paris, 268: 1.607-1.609.

DRACH, P. 1937. L'origine du calcaire dans les squelette tégumentaire des Crustacés Décapodes. Comp. Rend. Acad.Sc. Paris, 205: 1.441-1.443. 1939. Mue et cycle d'intermue chez les Crustacés Décapodes. Ann. Inst. Océanogr. Fr., 19: 103-391.

DRACH, P. \& LAFON, M. 1942. Etudes biochimiques sur le squelette tégumentajre des Décapodes Brachyoures. Variations au cours du cycle d'intermue, Arch. Zool. expér. gén. Fr., 82: 100-118.

DURFORT, M. 1975. Consideraciones sobre la estructura y ultraestructura del epitelio intestinal de Mytilicola intestinalis, Steuer. Vol. II, Cent. Real Soc. Esp. Hist. Nat., 109-120.

1977. Noves dades de la ultraestructura de l'cpiteli intestinal de Mytilicola intestinulis, Steuer. Butll. Soc. Cat. Biol, 1-2: 27-31.

1981 a. Localización y ultraestructura del glucógeno y de las inclusiones lipidicas en Mytilus edulis, L. (Mollusca, Bivalva) y en Trachydermon cinereus, Thiele (Mollusca, Poliplacophora). Iberus., 1: 79-84.

$1981 \mathrm{~b}$. Mineral concretions on the intestinal ephitelium of Cyclops strenuus, Fisch (Crustacea, Copepoda). Ultrastructural study. Butll. Inst. Cat. Hist. Nat., 47: 93-103.

1982. Las concresiones minerales del hepatopáncreas de Trachydermon cinereus, Thiele (Mollus. ca, Poliplacophora). Estudio ultraestructural. Iberus, $2: 1-17$.

GOURANTON, J. 1968. Composition, structure et mode de formation des concrétions minérales dans l'intestin moyen des Homoptères Cercopides. J. Cell. Biol., 37: 316-328.

GRAF, F. 1969. Le stockage de calcitum avant la mue chez les Crustacés Amphipodes Orchestia (Talitré) et Niphargus (Ganmaridé hypogé). Thèse Fac. Sciences Dijon, 216 págs.

1971. Dynamique du calcium dans l'épithelium des caecums postérieurs d'Orchestio cavimana Heller (Crustacé, Amphipode). Rôle de l'espace intercellulaire. Comp. Rend. Acad. SC. Paris, 273: 1.828-1.831.

1974. Quelques aspects du métabolisme du calcium chez les Crustacés. In: Physiologie comparée des échanges calciques, págs. 13-22. SIMEP, ed.

1978. Les sources de calcium pour les Crustacés venant de muer. Arch. Zool. exp. gén., 119: 143-161.

GRAF, F. \& MICHAUT, Ph. 1977. Les sphérules calciques de l'épithelium caecal d'Orchestia (Crustacé, Amphipode), forme de transport de calcium dans le sens apico-basal. Comp. Rend. Acad. Sc. Paris, 284: 49-52.

HUMBERT, W.1971.Localisation, structure et genè se des concrétions minérals dans la mésenteron des Collemboles Tomoceridae (Insecta, Collembola). Z. Morphol. Tiere, 78: 93-109.

1977. The mineral concretions in the mid gut of Tomocerus minor (Collembola): microprobe, analysis and physioecological significance. Rev. Ecol. Biol. Sol., 14: 71-80.

1978 a. Cytochemistry and X-Ray Microprobe Analysis of the Midgut of Tomocerus minor Lubbock (Insecta, Collembola) with special reference to the Physiological Significance of the Mineral Concretions. Cell. Tiss. Res., 187: $397-416$

1978 b. Intracellular and intramitochondrial binding of lanthanum in dark degenrating Midgut cells of a collembolan (Insect.) Histo. chemistry, 59: 117-128."

1979. The Midgut of Tomocerus minor Lubbock (Insecta, Collembola). Ultrastructure, cy tochemistry, ageing and renewal during a Moulting Cycle. Cell Tissue Res., 196: 39-57.

HUSSUN, R. 1952. A propos du rôle des gastrolithes chez les ecrevisses. Comp. Rend. Acad. SC., 235: 905-907.

JEANTET, A.Y.; MARTOJA, R. \& TRUCHET, M. 1974. Rôle des sphérocristaux de l'épithelium intestinal dans la résistance d'un Insecte aux pollutions minérales. Données expérimentales obtenues par utilisation de la microsonde électronique et du microanalyseur par émission ionique secondaire. Comp. Rend. Acad. Sc. Paris, $278: 1.441-1.444$.

JEANTET, A.Y.; BALLAN-DUFRANCAIS, Ch. \& RUSTE, J. 1980. Quantitative Electron Probe Microanalysis on Insects Exposed to Mercury. II.- Involvement of the Lysosomal System in Detoxification Processes. Biol. Cellulaire, 39: 325-334.

LANGA-REYREL, F. 1980. Analyse ultrastructurale des modifícations mésentériques liées à l'écomorphose chez Hypogastrusa tullbergi (Collemboles). Comp. Rend. Acad. Sc. Paris, 291: 345-347.

LHONORE, J. 1971. Données cytophysiologiques sur les tubes de Malpighi de Gryllotalpa gryllo. talpa, Latr. (Orthoptère, Gryllotalpidé). Comp. Rend. Acad. Sc., 272: 2.788-2.791.

1976 a. Données histophysiologiques sur les bioaccumulations minérales et puriques de Notonecta glauca, L. (Insecte, Hétéroptère). Annls. Limnol., 12: 127-138.

1976 a. Données morphologiques et histochimiques sur les tubes de Malpighi des imagos de Pieris brassicae, L. (Lepidoptère). Annls. Sc. Nat. Zool., 18: 275-293.

MARTOJA, R. 1971. Données préliminaires sur les accumulations de sels minéraux et de déchets du catabolisme dans quelques organes d'Artro- 
podes. Comp. Rend. Acatl. Sc. Paris, 273: 368371.

NATCH, C.M. 1972. On the storage of calcium in Spclaeomysis, a subterranean mysid. Crustaceana suppl. 3: 351-353.

PERRELET, A. \& BADER, C.R. 1978. Morphological Evidence for Calcium Stores in Photoreceptors of the Honeybee Drone Retina. $J$. Ultrast. Res., 63: 237-243.

PETFF, J. 1970. Sur la nature et l'accumulation de substances minérales dans les ovocytes de Poly. desmus complanatus (L) (Myriapode, Diplopode). Comp. Rend. Acad. Sc. Paris, 270: 2.107 2.110 .

RONDELAUD, D., CHAISEMARTIN, C. \& BARTHE, D. 1976. Données histologiques et histochimiques sur le transfert de deux metaux (Fet + t- $\mathrm{Cu}^{+}+$) chez Lymnaea (Galba) truncatula Muller (Mollusques, Gastéropodes, Pulmonés). Annls Limnol., 12: 269-281.

SOHAL, R.S.; PETERS, P.D, \& HALL, T.A. 1977.
Origin, structure, composition and age dependence of mineralized dense bodies (concretions) in the midgut epithelium of the adult housefly, Musca domestica. Tissue \& Cell, 9: 87-102.

TURBECK, B.O. 1974. A study of the concentrically laminated concretions "spherites" in the regenerative cells of the midgut of lepidopterus larvae. Tissue \& Cell., 6: 627-640.

WAKU, Y \& SUMIMOTO, K 1971. Metamorphosis of midgut epithelial cells in the silkworm (Bombyx mori, L.) with special regard to the calcium salt deposits in the cytoplasm. I. Light microscopy. Tissue \& Cell., 3: 127-136.

WIGGLESWORTH, V.B. \&. SALPETER, M.M. 1962. Histology of the Malpigian tubules in Rhodnius prolixus Stäl (Hemiptera). J. Insect. Physiol, 8: 299-307.

ZERBIB, C. 1980. Ultrastructural observation of Oogenesis in the Crustacea Amphipoda Orchestia gammarellus (Pallas). Tissue \& Cell., 12: 4762. 